\title{
ESTERCO LÍQUIDO DE BOVINOS LEITEIROS COMBINADO COM ADUBAÇÃO MINERAL SOBRE ATRIBUTOS QUÍMICOS DE UM LATOSSOLO BRUNO(1)
}

\author{
José Carlos Peixoto Modesto da Silva ${ }^{(2)}$, Antônio Carlos Vargas Motta ${ }^{(3)}$, \\ Volnei Pauletti ${ }^{(3)}$, Nerilde Favaretto ${ }^{(3)}$ Milena Barcellos $^{(4)}$, André Soares de \\ Oliveira $^{(5)}$, Cristina Mattos Veloso ${ }^{(6)}$ \& Luiz Fernando Costa e Silva ${ }^{(7)}$
}

\section{RESUMO}

Este trabalho foi conduzido com o objetivo de avaliar a influência de doses de adubação com esterco líquido de gado leiteiro, combinada com adubação mineral, sobre atributos químicos de um Latossolo Bruno, em sistema plantio direto e rotação de culturas de inverno e verão (sorgo/aveia-preta/milho/azevém/milho/azevém), para produção de silagem, nas camadas de 0-5, 5-10, 10-30, 30-50 e 50-80 cm de profundidade. Os tratamentos foram distribuídos em três blocos casualizados, divididos em 12 parcelas por bloco, em arranjo fatorial 3 x 4, sendo três doses de adubação mineral (0, 50 e $100 \%$ da dose recomendada para as culturas) e quatro doses de adubação orgânica $\left(0,30,60\right.$ e $\left.90 \mathrm{~m}^{3} \mathrm{ha}^{-1} \mathrm{ano}^{-1}\right)$. O esterco líquido aumentou o pH de forma linear na camada de 0-5 cm e quadrática na de 30-50 cm. A adubação mineral reduziu linearmente os valores de $\mathrm{pH}$ nas profundidades de 0-5 e 5-10 cm, havendo efeito quadrático na profundidade de $50-80 \mathrm{~cm}$. A acidez potencial diminuiu na profundidade de $5-10 \mathrm{~cm}$, com comportamento quadrático na profundidade de 10 a $30 \mathrm{~cm}$. Houve incremento do $\mathrm{Ca}^{2+}$ trocável na profundidade de 0-5 cm ao se adubar com esterco, mas não se verificou efeito da adubação mineral sobre este atributo. Observou-se aumento nos níveis $\mathbf{M g}^{2+}$ trocável nos tratamentos com esterco, até a profundidade de $30 \mathrm{~cm}$; já para o fertilizante mineral

\footnotetext{
(1) Parte da Dissertação de Mestrado apresentada pelo primeiro autor ao Departamento de Solos e Engenharia Agrícola, Universidade Federal do Paraná - UFPR. Recebido para publicação em agosto de 2007 e aprovado em setembro de 2008.

${ }^{(2)}$ Doutorando em Zootecnia, Universidade Federal de Viçosa - UFV. Av. PH Rolfs s/n, CEP 36570-000 Viçosa (MG). E-mail: jcpmodesto@yahoo.com.br

(3) Professores Adjuntos do Departamento de Solos e Engenharia Agrícola, Universidade Federal do Paraná - UFPR. Rua dos Funcionários 1540, CEP 80035-050 Curitiba (PR). E-mails: mottaacv@ufpr.br; vpauletti@ufpr.br; nfavaretto@ufpr.br

(4) Professora da Casa Familiar Rural de Santa Maria do Oeste. Santa Maria do Oeste (PR). E-mail: milena_barcellos@yahoo.com.br

(5) Doutor em Zootecnia, UFV. E-mail: andresoli@uol.com.br

(6) Professora Titular da Universidade Estadual do Sudoeste da Bahia - UESB. E-mail: cmveloso@uesb.br

(7) Graduanda em Zootecnia, UFV. Bolsista do CNPq. E-mail: ifcostasilva@yahoo.com.br
} 
os aumentos foram observados em profundidade superior a $30 \mathrm{~cm}$. Houve incremento linear da saturação por bases com o aumento das doses de esterco, até $10 \mathrm{~cm}$ de profundidade; a adubação mineral diminuiu a saturação por bases na profundidade de $5-10 \mathrm{~cm}$, havendo efeito quadrático na profundidade de $50-80 \mathrm{~cm}$.

Termos de indexação: adubação orgânica, rotação de culturas, fertilidade do solo, plantio direto.

\title{
SUMMARY: DAIRY CATTLE LIQUID MANURE COMBINED WITH MINERAL FERTILIZATION ON CHEMICAL PROPERTIES OF A BROWN OXISOL
}

\begin{abstract}
This study aimed to evaluate the influence of fertilization doses of liquid dairy manure combined with mineral fertilizer on the chemical properties of a Brown Oxisol, in no-tillage system and winter and summer crop rotation (sorghum/black-oat/corn/ryegrass/corn/ ryegrass), for silage production, in the layers $0-5,5-10,10-30,30-50$ and $50-80 \mathrm{~cm}$. The treatments were distributed in three randomized blocks, divided in 12 plots per block, in a $3 \times 4$ factorial arrangement, with three mineral fertilizer levels $(0,50$ and $100 \%$ of the dose recommended for the crops) and four organic fertilizer levels (0, 30, 60 and $90 \mathrm{~m}^{3} \mathrm{ha}^{-1}$ year-1). The liquid dairy manure increased the $\mathrm{pH}$ linearly in the $0-5 \mathrm{~cm}$ layer and quadratic in the $30-50 \mathrm{~cm}$ layer. The mineral fertilization reduced the $\mathrm{pH}$ values linearly in the $0-5$ and 5-10 cm layers, with quadratic effect at 50-80 cm. The potential acidity decreased in $5-10 \mathrm{~cm}$, with quadratic pattern at $10-30 \mathrm{~cm}$. The exchangeable $\mathrm{Ca}^{2+}$ increased in the $0-5 \mathrm{~cm}$ layer with manure, but no effect of mineral fertilization on this attribute was verified. An increase in exchangeable $\mathrm{Mg}^{2+}$ levels was observed in the manure treatments to a depth of $30 \mathrm{~cm}$; under mineral fertilizer, increases were observed from $30 \mathrm{~cm}$ downwards. There was a linear increase of base saturation through manure doses, down to a depth of $10 \mathrm{~cm}$, and the mineral fertilization decreased base saturation at 5-10 cm, with a quadratic effect at $50-80 \mathrm{~cm}$.
\end{abstract}

Index terms: organic fertilization, crop rotation, soil fertility, no-tillage.

\section{INTRODUÇÃO}

A elevada acidez do solo constitui um dos principais fatores que limitam a produtividade de um sistema agrícola, influenciando direta e indiretamente as reações químicas e a atividade biológica dos solos. Essa acidificação ocorre, freqüentemente, pelo processo de nitrificação de formas amoniacais ou amídicas de adubos minerais e orgânicos. A liberação do íon hidrogênio no processo de formação do nitrato acidifica a camada superficial do solo, no caso de plantio direto, ou a camada arável, quando incorporado (Fox \& Hoffman, 1981; Follett \& Peterson., 1988; McVay et al., 1989; Ismail et al., 1994; Juo et al., 1995). Além disso, solos cultivados podem ter aumento da acidez, em conseqüência do processo de erosão, extração de cátions básicos pelas culturas e lixiviação de bases, que, por meio da participação de ânions, atuam como carreadores dos cátions (Raij, 1991).

A maneira mais comumente utilizada para diminuir a acidez do solo é o uso de calcário. Contudo, alguns trabalhos têm demonstrado aumento do $\mathrm{pH}$ após a utilização de resíduos orgânicos de animais. Vitosh et al. (1973), utilizando esterco de gado, constataram acréscimos no $\mathrm{pH}$ quando da aplicação de esterco após um período de nove anos, sob condição de campo. Whalen et al. (2000), trabalhando sob controle, também constataram aumento do $\mathrm{pH}$ do solo com a aplicação de esterco. Ainda, Hoyt \& Turner (1975) e Hue \& Amien (1989) relatam que a adição de resíduos vegetais pode diminuir a acidez do solo.

Whalen et al. (2000) afirmam que modificações no $\mathrm{pH}$ de solos, com adição de esterco bovino, são devidas não só ao tamponamento por carbonatos e bicarbonatos, mas também a outros compostos, como os ácidos orgânicos com grupos carboxil e hidroxil fenólicos, os quais têm importante papel no tamponamento da acidez do solo e na variação do $\mathrm{pH}$ de solos ácidos manejados com esterco. A alteração do $\mathrm{pH}$, pela aplicação de resíduos orgânicos, segundo Raij (1991), pode estar relacionada com: (a) o alto podertampão do material orgânico; (b) a possível neutralização do $\mathrm{Al}$; (c) o efeito da saturação de bases, estimulando a manutenção ou a formação de certas 
bases permutáveis, como $\mathrm{Ca}, \mathrm{Mg}, \mathrm{Ke} \mathrm{Na}$, contribuindo para redução da acidez e aumento da alcalinidade; (d) uma relação positiva com a capacidade de troca catiônica.

Embora com menor freqüência, a não-alteração do pH (Schjonning et al., 1994) ou mesmo a acidificação (King et al., 1974; Chang et al., 1990, 1991) foram constatadas após a aplicação de esterco.

$\mathrm{O}$ excesso de íons $\mathrm{H}^{+}$e ânions $\mathrm{NO}_{3}^{-}$, na solução do solo, faz com que aumente a lixiviação de bases, na forma de sais de $\mathrm{Ca}^{2+}, \mathrm{Mg}^{2+}$ e $\mathrm{K}^{+}$no solo (Grove, 1986), incrementando os teores desses elementos em profundidade. A adição de resíduos orgânicos na forma de restos de culturas ou esterco de animais tem propiciado, em diversas condições, maior movimentação de cátions em profundidade (Kingery et al., 1994).

A perda de bases para as camadas mais profundas pode, em alguns casos, favorecer o desenvolvimento radicular das plantas (Stone \& Silveira, 2001), permitindo maior capacidade de absorção de água e nutrientes do solo (Pavan, 1999), tendo como conseqüência maior resistência a condições climáticas adversas e melhor aproveitamento dos nutrientes.

Este trabalho teve como objetivo avaliar a influência do esterco líquido de gado leiteiro, combinado com adubação mineral, nos atributos químicos de um Latossolo Bruno em sistema plantio direto, em cinco profundidades do solo $(0-5,5-10,10$ $30,30-50$ e 50-80 cm), numa área adubada por longo período (seis anos).

\section{MATERIAL E MÉTODOS}

O experimento foi instalado na Fazenda Capão-Alto, no município de Castro-PR, no período de março de 1997 a julho de 2003, em área experimental da Fundação ABC (Arapoti, Batavo e Castrolanda). Localiza-se na região fisiográfica denominada de Terceiro Planalto Paranaense, entre as coordenadas $24^{\circ} 50$ ' de latitude sul e $49^{\circ} 50$ ' de longitude oeste e altitude média de $900 \mathrm{~m}$. O clima da região, segundo a classificação climática de Köppen, é do tipo Cfb, clima temperado propriamente dito, registrando temperaturas médias dos meses mais frios entre $13{ }^{\circ} \mathrm{C}$ e $14{ }^{\circ} \mathrm{C}$ e temperaturas médias nos meses mais quentes entre 23 e $24^{\circ} \mathrm{C}$, sem estação seca definida, com pluviosidade anual entre 1.400 a $1.600 \mathrm{~mm}$, sendo a média nos trimestres mais secos entre 250 e $350 \mathrm{~mm}$ e nos trimestres mais chuvosos entre 400 e $500 \mathrm{~mm}$. A umidade relativa média do ar apresenta-se entre $70 \mathrm{e}$ $75 \%$, e a evapotranspiração média anual entre 900 e $1.000 \mathrm{~mm}$. A vegetação original é caracterizada por campo subtropical dos Campos Gerais do Paraná (IAPAR, 2000).

O tipo de solo, de acordo com a classificação da Embrapa (1999), é caracterizado como Latossolo Bruno distroférrico textura argilosa fase campo subtropical, com relevo suavemente ondulado. As características químicas médias do solo, por ocasião da instalação do experimento, podem ser observadas no quadro 1. Convém salientar que a área apresentava, anteriormente ao período de estudo, histórico de 16 anos de adubação orgânica com esterco, em sistema plantio direto, e intensa rotação de culturas típicas da região, tendo sido plantado, no verão, principalmente milho e soja e, no inverno cereais e forrageiras. Esses fatores são determinantes da elevada fertilidade apresentada pelo solo antes do experimento.

Os tratamentos foram distribuídos em três blocos casualizados divididos em 12 parcelas por bloco, em arranjo fatorial $3 \times 4$, com três doses de adubação mineral (0, 50 e $100 \%$ da dose recomendada para as culturas) e quatro doses de adubação orgânica $(0,30$, $\left.60,90 \mathrm{~m}^{3} \mathrm{ha}^{-1} \mathrm{ano}^{-1}\right)$. Procedeu-se à correção do solo antes do experimento, com calcário dolomítico, na proporção de $1 \mathrm{t} \mathrm{ha}^{-1}$, sendo feita a lanço, sem incorporação; após 30 dias, foi realizado o plantio.

A adubação mineral foi baseada na análise inicial do solo; a quantidade de adubo mineral correspondente a $100 \%$ do recomendado para as culturas, sem aplicação de esterco, encontra-se no quadro 2 .

O esterco utilizado foi proveniente da criação de gado leiteiro, em sistema intensivo de manejo em galpões de confinamento (Free stall), sendo composto pela mistura de fezes e urina dos animais, além de outros materiais provenientes do processo criatório, como água desperdiçada nos bebedouros, água de higienização e restos de alimentos. Os dejetos foram

Quadro 1. Atributos químicos do solo da área de estudo, antes da instalação do experimento

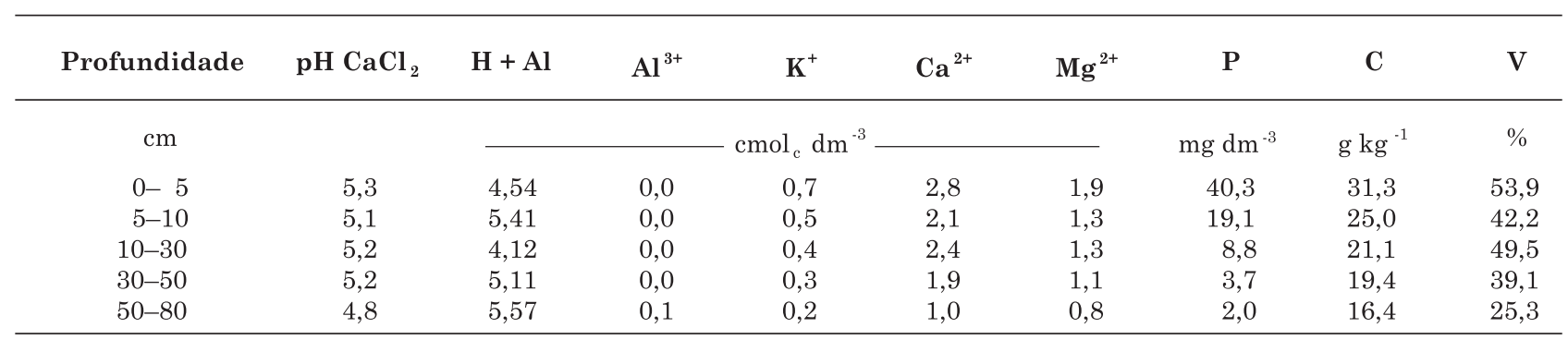


armazenados em esterqueiras, próximas ao galpão de confinamento, e homogeneizados diariamente. $\mathrm{O}$ transporte do esterco líquido de gado leiteiro foi feito por meio de trator, com vagão contendo rosca-semfim, que permite a homogeneização do esterco quando este está sendo transportado para o campo. Foram utilizadas doses de 0, 30, 60 e $90 \mathrm{~m}^{3} \mathrm{ha}^{-1} \mathrm{ano}^{-1}$, aplicadas metade nas forrageiras de inverno e o restante nas de verão, manualmente em superfície e sem incorporação. As características do esterco, de três amostras coletadas no período do experimento, são apresentadas no quadro 3, e a quantidade de nutrientes adicionados ao solo, no período de sete anos, por meio da aplicação de $30 \mathrm{~m}^{3} \mathrm{ha}^{-1}$ de esterco líquido de gado leiteiro, foi de aproximadamente 228,372 e $618 \mathrm{~kg} \mathrm{ha}^{-1}$ de $\mathrm{N}, \mathrm{P}_{2} \mathrm{O}_{5}$ e $\mathrm{K}_{2} \mathrm{O}$, respectivamente. A rotação de culturas e cultivares é apresentada no quadro 4, com os respectivos anos de plantio. As plantas foram cortadas e ensiladas, para posterior fornecimento no cocho aos animais.

A coleta de solo foi feita no inverno de 2003, em cinco profundidades $(0-5,5-10,10-30,30-50$ e 50$80 \mathrm{~cm})$; nas profundidades de $0-5,5-10$ e 10-30 cm, foram retiradas 15 amostras simples para fazer uma amostra composta, utilizando trado calador, e nas profundidades de 30-50 e 50-80 cm foram retiradas cinco amostras simples para fazer uma amostra composta, utilizando-se o trado holandês. As amostras foram coletadas aleatoriamente nas parcelas, com os cuidados recomendados para a não contaminação das amostras superiores, como limpeza de profundidade de amostras, no sentido das profundidades maiores para as menores.

Quadro 2. Quantidade de N, $\mathrm{P}_{2} \mathrm{O}_{5}$ e $\mathrm{K}_{2} \mathrm{O}$ aplicada, correspondente a $100 \%$ da adubação mineral no plantio e na cobertura das culturas, de verão e inverno

\begin{tabular}{|c|c|c|c|c|c|}
\hline \multirow{2}{*}{ Cultura } & \multicolumn{3}{|c|}{ Dose de plantio } & \multicolumn{2}{|c|}{ Dose de cobertura } \\
\hline & $\mathbf{N}$ & $\mathbf{P}_{2} \mathbf{O}_{5}$ & $\mathbf{K}_{2} \mathbf{O}$ & $\mathbf{N}$ & $\mathbf{K}_{2} \mathbf{O}$ \\
\hline & & & $\mathrm{kg} \mathrm{ha}^{-1}$ & & - \\
\hline Sorgo & 30 & 60 & 60 & 90 & 0 \\
\hline Milho & 30 & 60 & 60 & 90 & 0 \\
\hline Aveia Preta & 20 & 60 & 60 & 37.5 & 37.5 \\
\hline Azevém & 16 & 45 & 0 & 77.5 & 0 \\
\hline Total $(6 \text { anos })^{(1)}$ & 284 & 660 & 480 & 925 & 75 \\
\hline
\end{tabular}

(1) Calculado considerando as culturas de inverno e verão e os anos de cultivo.

Quadro 3. Teores de matéria seca (MS) e totais dos nutrientes ${ }^{(1)}$ de três amostras de esterco avaliadas no período experimental

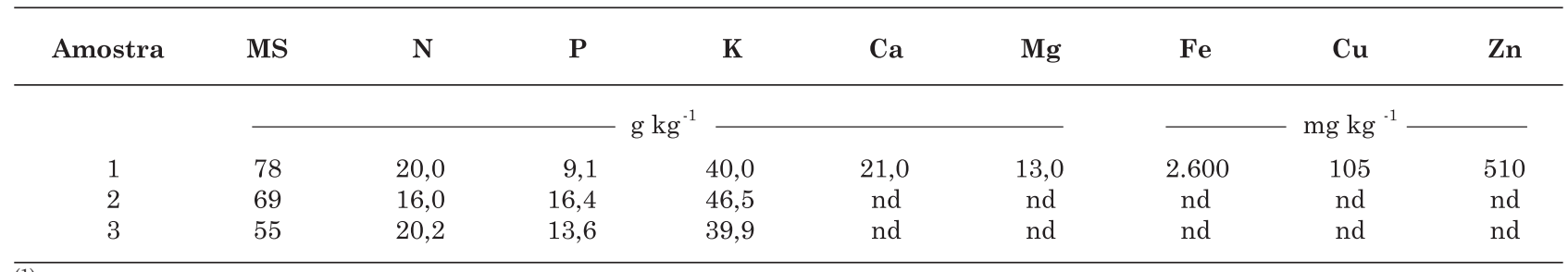

(1) Teor de nutrientes em base seca.

Quadro 4. Rotação de culturas de verão e inverno na área experimental entre 1997 e 2003

\begin{tabular}{|c|c|c|c|}
\hline \multirow{2}{*}{$\begin{array}{c}\text { Ano } \\
\text { plantio }\end{array}$} & \multicolumn{3}{|c|}{ Forrageira } \\
\hline & Verão & Inverno & \\
\hline $97 / 98$ & Sorgo AG 2005 (Sorghum vulgare Pers.) & Aveia-Preta comum (Avena strigosa & Sereb) \\
\hline $98 / 99$ & Milho AG 9012 (Zea mays L.) & Azevém comum (Lolium multiflorum & Lam.) \\
\hline $99 / 00$ & Milho AG 9012 (Zea mays L.) & Azevém comum (Lolium multiflorum & Lam.) \\
\hline $00 / 01$ & Sorgo AG 2005(Sorghum vulgare Pers.) & Aveia-Preta comum ( Avena strigosa & Sereb) \\
\hline $01 / 02$ & Milho AG 9012 (Zea mays L.) & Azevém comum (Lolium multiflorum & Lam.) \\
\hline $02 / 03$ & Milho AG 9012 (Zea mays L.) & Azevém comum (Lolium multiflorum & Lam.) \\
\hline
\end{tabular}


Para determinação do $\mathrm{pH}$, utilizou-se leitura potenciométrica em solução de $\mathrm{CaCl}_{2} 0,01 \mathrm{~mol} \mathrm{~L}^{-1}$, relação solo/solução 1:2,5. A acidez potencial $(\mathrm{H}+\mathrm{Al})$ foi estimada por meio da leitura do $\mathrm{pH}$ após a adição de solução tamponada SMP às amostras de solo, utilizando-se calibração apropriada. $\mathrm{O} \mathrm{Ca}^{2+} \mathrm{e} \mathrm{o} \mathrm{Mg}^{2+}$ foram extraídos com $\mathrm{KCl} 1 \mathrm{~mol} \mathrm{~L}^{-1}$ e quantificados por espectrofotometria de absorção atômica. Todas as determinações foram realizadas nos laboratórios da UFPR, seguindo método descrito por Marques \& Motta (2003).

Os dados foram submetidos a análises de variância e regressão, adotando-se o nível de $5 \%$ para o erro tipo I, utilizando-se o programa Statistical Analysis System (SAS, 1996). Nos casos em que a interação adubação mineral $\times$ adubação orgânica não foi significativa, efetuou-se o estudo de regressão de primeiro e segundo graus, por meio do comando GLM. As relações significativas foram ilustradas em gráficos.

\section{RESULTADOS E DISCUSSÃO}

No quadro 5 são mostrados os efeitos dos tratamentos para $\mathrm{pH}\left(\mathrm{CaCl}_{2}\right)$, acidez potencial $(\mathrm{H}+\mathrm{Al}), \mathrm{Ca}^{2+}$ e $\mathrm{Mg}^{2+}$ trocável e $\mathrm{V}$, nas diversas profundidades analisadas neste experimento, e seus coeficientes de variação. Os resultados indicaram não haver interação entre adubação orgânica e adubação mineral sobre a acidez, em nenhuma profundidade avaliada.

O efeito da adubação orgânica sobre o $\mathrm{pH}$ ocorreu na camada superficial de $0-5 \mathrm{~cm}$ e na profundidade de 30-50 cm (Quadro 5). Na camada de 0-5 cm, para cada $\mathrm{m}^{3}$ de esterco aplicado anualmente, houve aumento linear médio de 0,0047 unidade na escala de $\mathrm{pH}$ após seis anos de aplicações (Figura 1a e Quadro 6). Já na profundidade de $30-50 \mathrm{~cm}$, o aumento na escala de $\mathrm{pH}$ para adição de esterco foi até o nível de $62 \mathrm{~m}^{3}$ (Figura 1a). Após essa quantidade, $\mathrm{o} \mathrm{pH}$ decresce à medida que se adiciona esterco. Não se observou efeito da adubação orgânica sobre o pH nas camadas entre 5 e $30 \mathrm{~cm}$ e 50 e $80 \mathrm{~cm}$. Sob plantio direto, observa-se, em geral, aumento da densidade e da resistência à penetração nas camadas imediatamente abaixo da superfície, indicando uma provável diminuição da porosidade do solo (Hammel, 1989; Motta, 2002). Desse modo, é possível que, com o auxílio de canais preferenciais, comuns em áreas de plantio direto, parte dos produtos neutralizantes responsáveis pelo acréscimo do $\mathrm{pH}$ na camada de 30 $50 \mathrm{~cm}$ tenha sido transportada diretamente da superfície para esta camada, o mesmo não acontecendo com as camadas nas quais não houve alteração nos valores de $\mathrm{pH}$.

Corroborando os resultados aqui obtidos, acréscimos de $\mathrm{pH}$ com uso de esterco bovino têm sido relatados sob controle (Olsen et al., 1970; Iyamuremye et al., 1996; Whale et al., 2000) e em campo (Vistosh et al., 1973). Josan et al. (2005) também constataram maiores valores de $\mathrm{pH}$ em áreas com atividade de gado de leite do que em áreas abandonadas, indicando possível efeito do esterco sobre o aumento do $\mathrm{pH}$ do solo. O uso de esterco de frango também proporcionou acréscimo do $\mathrm{pH}$, em solos arenosos, até a camada de $60 \mathrm{~cm}$, após aplicações contínuas por mais de 15 anos (Kingery et al., 1994).

No entanto, King et al. (1974) não encontraram efeito da adição de esterco de aves, em relação ao $\mathrm{pH}$, até a profundidade de $15 \mathrm{~cm}$, havendo decréscimo do $\mathrm{pH}$ na profundidade de $15-30 \mathrm{~cm}$. Decréscimo até $60 \mathrm{~cm}$ de profundidade foi observado por Chang et al. (1991), após 11 anos de aplicações de doses crescentes de esterco de gado de corte, em solos alcalinos. Ernani \& Gianello (1983), trabalhando em casa de vegetação com aplicação de esterco de aves e gado de leite ao solo, também não perceberam alteração do $\mathrm{pH}$ nos diversos tratamentos analisados, verificando diminuição do teor de Al trocável no solo com o aumento do material orgânico aplicado.

Já para adubação mineral (Quadro 5), observouse pequeno decréscimo no valor do $\mathrm{pH}$, nas profundidades de $0-5$ e $5-10 \mathrm{~cm}$. Esses resultados estão de acordo com a maioria daqueles citados na literatura (Paiva et al., 1996; Abreu Júnior et al., 2000) quanto ao uso de fertilizantes minerais, pois há tendência de diminuição dos valores de $\mathrm{pH}$ devido ao efeito ácido da nitrificação do amônio, ficando este geralmente restrito aos primeiros centímetros da camada superficial. Na profundidade de $50-80 \mathrm{~cm}$, observou-se ligeiro aumento do $\mathrm{pH}$, atingindo o ponto máximo com a dose de $60 \%$ de adubação mineral (Figura 1b). Após esta dose de adubação, entretanto, as respostas foram negativas.

Não foi possível verificar o efeito do esterco sobre a acidez trocável ( $\mathrm{Al}^{3+}$ trocável) devido ao valor de $\mathrm{pH}$ em $\mathrm{CaCl}_{2}$ estar próximo de 5,0, quando o $\mathrm{Al}^{3+}$ geralmente encontra-se precipitado na forma de hidróxido de alumínio, $\mathrm{Al}(\mathrm{OH})_{3}$ (Raij, 1991).

A acidez potencial $(\mathrm{H}+\mathrm{Al})$ teve comportamento inverso ao do $\mathrm{pH}$ na profundidade de $0-5 \mathrm{~cm}$ (Figura 2a), como era esperado, observando-se redução da acidez potencial pelo uso de esterco. Os resultados aqui obtidos corroboram os de Hoyt \& Turner (1975), Holanda et al. (1982), Hue (1992) e Iyamuremye et al. (1996), que também observaram decréscimo da acidez potencial, trabalhando com esterco animal.

Na profundidade de 5-10 cm, há diminuição da acidez potencial em função da adubação mineral (Figura 2b). Já na profundidade de $10-30 \mathrm{~cm}$, o gráfico (Figura $2 \mathrm{~b}$ ) mostra que o ponto máximo onde ocorreu elevação da acidez potencial é com dose de $42 \%$ da recomendada; após esse limite, ocorre diminuição da acidez potencial. Nas demais profundidades, não houve efeito da adubação mineral sobre a acidez potencial. 
Quadro 5. Efeito dos tratamentos de adubação orgânica e mineral sobre o pH $\left(\mathrm{CaCl}_{2}\right)$, acidez potencial

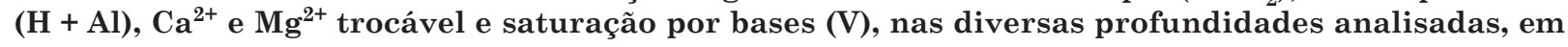
Latossolo Bruno sob sistema plantio direto

\begin{tabular}{|c|c|c|c|c|c|c|}
\hline \multirow{3}{*}{ Variável-resposta } & \multirow{3}{*}{ Profundidade } & \multicolumn{5}{|c|}{ Efeito } \\
\hline & & \multicolumn{2}{|c|}{ Mineral } & \multicolumn{2}{|c|}{ Esterco } & \multirow[t]{2}{*}{$\mathrm{CV}$} \\
\hline & & $\mathbf{L}^{(1)}$ & $\mathbf{Q}^{(2)}$ & $\mathbf{L}$ & $\mathbf{Q}$ & \\
\hline \multirow{6}{*}{$\mathrm{pH} \mathrm{CaCl}{ }_{2}$} & $\mathrm{~cm}$ & & & & & $\%$ \\
\hline & $0-5$ & * & $\mathrm{ns}$ & $*$ & $\mathrm{~ns}$ & 2,30 \\
\hline & $5-10$ & * & $\mathrm{ns}$ & $\mathrm{ns}$ & $\mathrm{ns}$ & 3,28 \\
\hline & $10-30$ & ns & $\mathrm{ns}$ & $\mathrm{ns}$ & $\mathrm{ns}$ & 2,39 \\
\hline & $30-50$ & ns & $\mathrm{ns}$ & * & $*$ & 2,90 \\
\hline & $50-80$ & $\mathrm{~ns}$ & $*$ & ns & $\mathrm{ns}$ & 3,66 \\
\hline \multirow{5}{*}{$\begin{array}{l}\text { Acidez potencial }(\mathrm{H}+\mathrm{Al}) \\
\left(\mathrm{cmol}_{\mathrm{c}} \mathrm{dm}^{-3}\right)\end{array}$} & $0-5$ & $\mathrm{~ns}$ & $\mathrm{~ns}$ & $*$ & $\mathrm{~ns}$ & 11,73 \\
\hline & $5-10$ & $*$ & $\mathrm{~ns}$ & $\mathrm{~ns}$ & $\mathrm{~ns}$ & 12,18 \\
\hline & $10-30$ & ns & $*$ & $\mathrm{~ns}$ & $\mathrm{~ns}$ & 9,74 \\
\hline & $30-50$ & ns & $\mathrm{ns}$ & $\mathrm{ns}$ & $\mathrm{ns}$ & 20,24 \\
\hline & $50-80$ & ns & $\mathrm{ns}$ & ns & $\mathrm{ns}$ & 9,91 \\
\hline \multirow[t]{5}{*}{ Cálcio trocável $\left(\mathrm{cmol}_{\mathrm{c}} \mathrm{dm}^{-3}\right)$} & $0-5$ & $\mathrm{~ns}$ & $\mathrm{~ns}$ & $*$ & $\mathrm{~ns}$ & 12,89 \\
\hline & $5-10$ & ns & $\mathrm{ns}$ & ns & $\mathrm{ns}$ & 20,31 \\
\hline & $10-30$ & ns & $\mathrm{ns}$ & $\mathrm{ns}$ & $\mathrm{ns}$ & 8,75 \\
\hline & $30-50$ & $\mathrm{~ns}$ & $\mathrm{~ns}$ & $\mathrm{~ns}$ & $\mathrm{~ns}$ & 16,39 \\
\hline & $50-80$ & ns & $\mathrm{ns}$ & ns & ns & 15,10 \\
\hline \multirow[t]{5}{*}{ Magnésio trocável $\left(\mathrm{cmol}_{\mathrm{c}} \mathrm{dm}^{-3}\right)$} & $0-5$ & $\mathrm{~ns}$ & $\mathrm{~ns}$ & $*$ & $\mathrm{~ns}$ & 14,00 \\
\hline & $5-10$ & ns & $\mathrm{ns}$ & $*$ & $\mathrm{~ns}$ & 12,23 \\
\hline & $10-30$ & ns & $\mathrm{ns}$ & $*$ & $\mathrm{~ns}$ & 12,26 \\
\hline & $30-50$ & $\mathrm{~ns}$ & $*$ & $\mathrm{~ns}$ & $\mathrm{~ns}$ & 14,28 \\
\hline & $50-80$ & ns & * & $\mathrm{ns}$ & ns & 21,68 \\
\hline \multirow[t]{5}{*}{ Saturação por bases (\%) } & $0-5$ & ns & $\mathrm{ns}$ & $*$ & $\mathrm{~ns}$ & 7,99 \\
\hline & $5-10$ & $*$ & $\mathrm{~ns}$ & $*$ & $\mathrm{~ns}$ & 6,64 \\
\hline & $10-30$ & ns & $\mathrm{ns}$ & $\mathrm{ns}$ & $\mathrm{ns}$ & 8,19 \\
\hline & $30-50$ & ns & $\mathrm{ns}$ & ns & $\mathrm{ns}$ & 15,34 \\
\hline & $50-80$ & ns & * & $\mathrm{ns}$ & $\mathrm{ns}$ & 17,15 \\
\hline
\end{tabular}

${ }^{(1)}$ L: efeito linear. ${ }^{(2)} \mathrm{Q}$ : efeito quadrático. ns: não-significativo a $5 \%$ pelo teste $\mathrm{F}$; * significativo a $5 \%$ pelo teste $\mathrm{F}$.
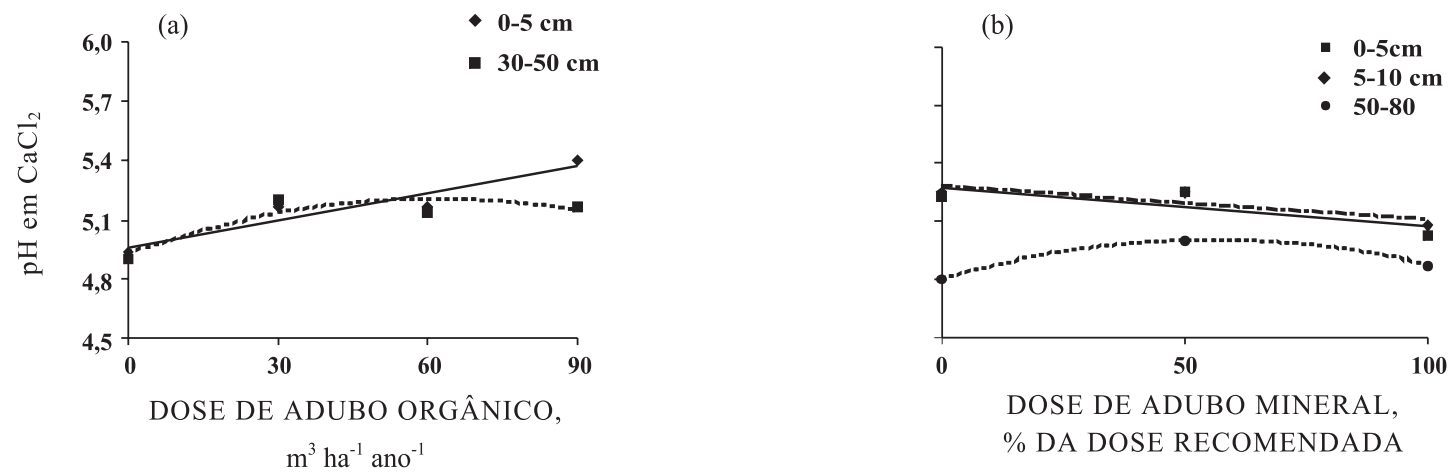

Figura 1. Valores de $\mathrm{pH} \mathrm{CaCl}_{2}$ em Latossolo Bruno sob plantio direto submetido a diferentes doses de esterco líquido de gado leite e adubação mineral, por um período de seis anos, com remoção total da planta: (a) adubação orgânica; (b) adubação mineral.

O decréscimo da acidez potencial na camada de 5$10 \mathrm{~cm}$ não era esperado, visto que nela ocorreu diminuição do $\mathrm{pH}$. Isso pode ter ocorrido devido à deficiência na estimativa dos teores de $\mathrm{H}+\mathrm{Al}$ por meio do valor do $\mathrm{pH}$ em SMP, que pode não ter sido suficientemente sensível para detectar, com exatidão, diferenças devidas aos tratamentos.
Conforme esperado, os resultados mostraram que não houve efeito significativo da adubação mineral sobre os teores de $\mathrm{Ca}^{2+}$ trocável em nenhum dos tratamentos analisados, nas cinco profundidades estudadas (Quadro 5). A adubação com esterco aumentou linearmente os teores de $\mathrm{Ca}^{2+}$ apenas na camada de 0-5 cm (Quadro 5), mostrando que, para 
Quadro 6. Equações de regressão para $\mathrm{pH}\left(\mathrm{CaCl}_{2}\right)$, acidez potencial $(\mathrm{H}+\mathrm{Al}), \mathrm{Ca}^{2+}, \mathrm{Mg}^{2+}$ trocável e saturação de bases (V) em sistema plantio direto submetido a diferentes doses de esterco líquido de gado de leite e adubação mineral

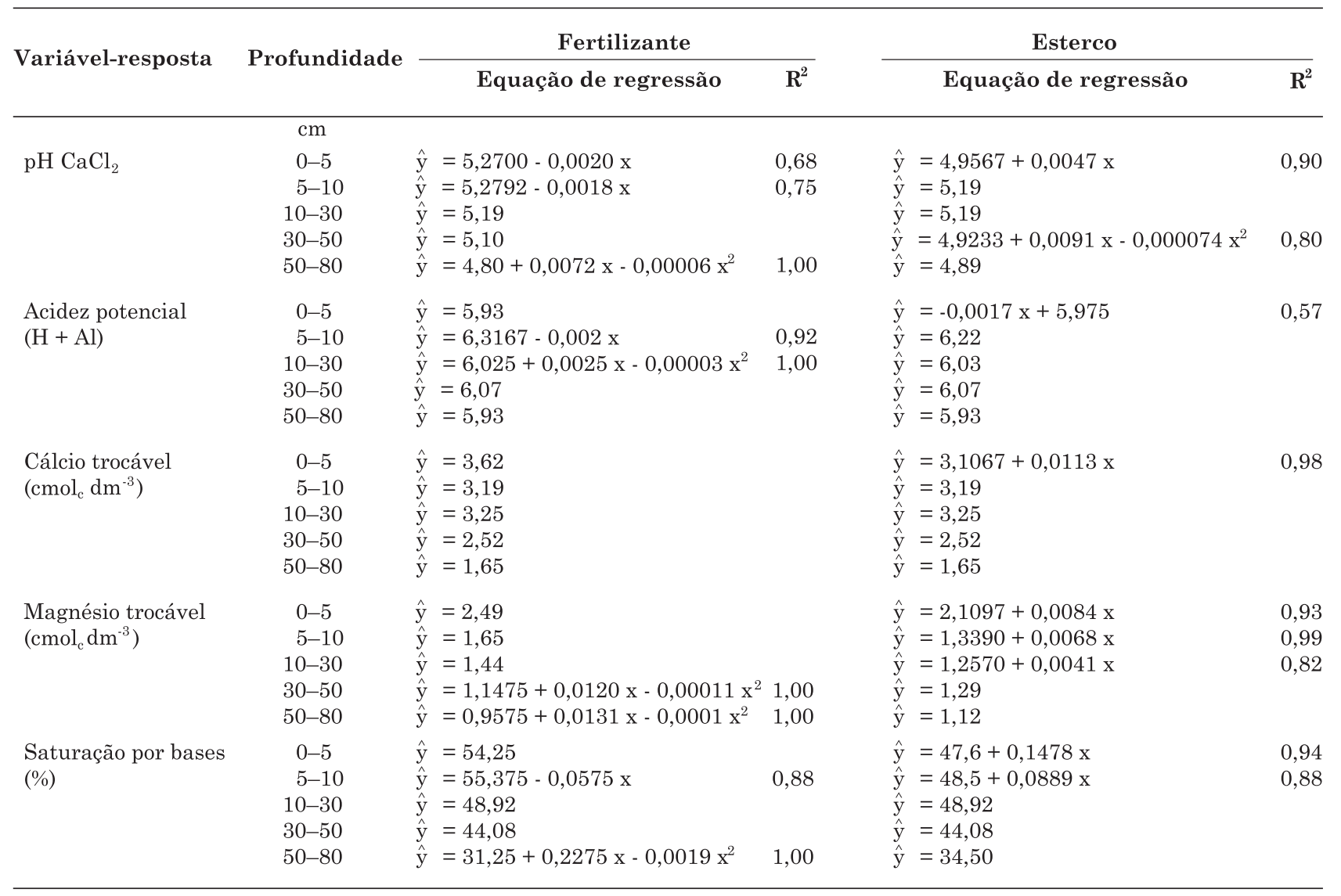
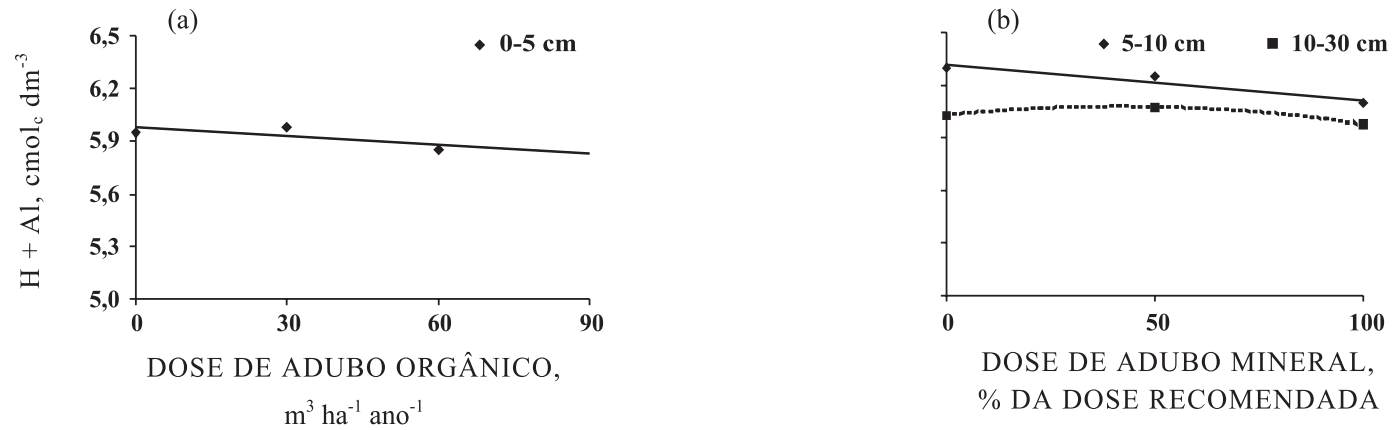

Figura 2 .Acidez potencial $(\mathrm{H}+\mathrm{Al})$ em Latossolo Bruno sob plantio direto submetido a diferentes doses de esterco líquido de gado leiteiro e adubação mineral, por um período de seis anos, com remoção total da planta: (a) adubação orgânica; (b) adubação mineral.

cada $\mathrm{m}^{3}$ de esterco adicionado anualmente ao solo, houve acréscimo no Ca trocável de 0,0113 $\mathrm{cmol}_{\mathrm{c}} \mathrm{dm}^{-3}$ após o período de seis anos (Figura 3 e Quadro 6).

Observou-se aumento linear significativo para o $\mathrm{Mg}^{2+}$ com o incremento das doses de esterco líquido de gado de leiteiro até os $30 \mathrm{~cm}$ de profundidade (Quadro 5), sendo os valores mais altos na camada de
0-5 cm. Já a adubação mineral proporcionou alterações no teor de $\mathrm{Mg}^{2+}$ apenas em profundidades superiores a $30 \mathrm{~cm}$. É interessante observar que o $\mathrm{Mg}^{2+}$ aumenta, na profundidade de $30-50 \mathrm{~cm}$, até o ponto correspondente a $55 \%$ da dose máxima de adubo mineral; após esse ponto, há decréscimo nos valores de $\mathrm{Mg}^{2+}$. Na profundidade de $50-80 \mathrm{~cm}$, o aumento ocorre até o ponto de $65 \%$, depois do qual o $\mathrm{Mg}^{2+}$ 


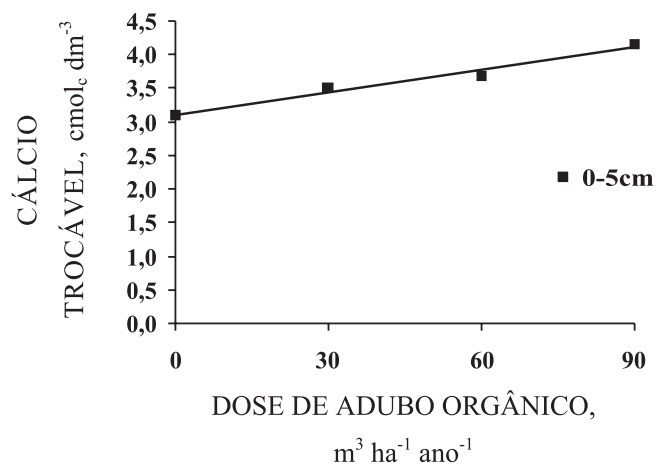

Figura 3. Teor de cálcio trocável em em Latossolo Bruno sob plantio direto submetido a diferentes doses de esterco líquido de gado leiteiro, por um período de seis anos, com remoção total da planta.

começa a decrescer. Ou seja, o comportamento do teor de $\mathrm{Mg}^{2+}$ em adubação com esterco é linear, enquanto com adubação mineral é quadrático (Figura 4a,4b).

$\mathrm{O}$ aumento do $\mathrm{Mg}^{2+}$ numa profundidade maior do que o de $\mathrm{Ca}^{2+}$ e o efeito quadrático do $\mathrm{Mg}^{2+}$ nas profundidades de 30-50 e 50-80 cm (Figura 4b), com decréscimo na dose máxima de adubo mineral, provavelmente se devem à menor força de adsorção deste íon em relação ao $\mathrm{Ca}^{2+}$, como relatado por Loyola \& Pavan (1989), favorecendo assim a lixiviação do $\mathrm{Mg}^{2+}$ para camadas mais profundas.

Há de se considerar, entretanto, que os efeitos da adubação mineral sobre o $\mathrm{Mg}^{2+}$ trocável do solo devem ser indiretos, já que esse elemento não é encontrado nas formulações dos adubos minerais utilizados. Assim, pressupõe-se que esse íon seja proveniente da dissolução do calcário dolomítico aplicado previamente à superfície, cujo deslocamento pode ter sido favorecido pela competição com o K aplicado na adubação mineral.

Corroborando os resultados aqui obtidos, acréscimos de $\mathrm{Ca}^{2+} \mathrm{e} \mathrm{Mg}^{2+}$ trocável sob controle (Olsen et al., 1970; Whalen et al., 2000) e em campo (Vitosh et al., 1973; Warman, 1987; Chang et al., 1991; Josan et al., 2005) foram observados em diferentes solos onde se aplicou esterco. Chang et al. (1991), após 11 anos de aplicação de esterco de gado de corte, constataram aumento do teor de $\mathrm{Ca}^{2+}+\mathrm{Mg}^{2+}$ trocável, sendo os maiores teores obtidos entre $30-60$ e $60-90 \mathrm{~cm}$ de profundidade, sem e com irrigação, respectivamente, indicando grande mobilidade desses elementos no solo.

Todavia, o efeito do uso de esterco, em longo prazo, tem afetado camadas de solo mais profundas do que as observadas neste trabalho. Kingery et al. (1994), trabalhando com esterco de aves em solos arenosos, constataram aumento dos teores de $\mathrm{Ca}^{2+}$ até uma profundidade de $140 \mathrm{~cm}$, mostrando a mobilidade do $\mathrm{Ca}^{2+}$ no perfil do solo. No mesmo trabalho, constatouse incremento dos níveis de $\mathrm{Mg}^{2+}$ até a profundidade de $290 \mathrm{~cm}$, sendo o efeito mais pronunciado nos primeiros $15 \mathrm{~cm}$ de profundidade, confirmando assim a maior mobilidade do $\mathrm{Mg}^{2+}$ em relação ao $\mathrm{Ca}^{2+}$. Esses

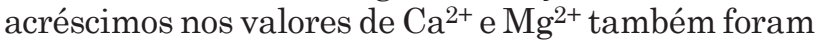
verificados por Franchini et al. (1999), trabalhando com resíduos vegetais, e Anjos \& Mattiazzo (2000), com lodo de esgoto. Possivelmente, a menor lixiviação desses elementos no caso estudado deve-se ao alto poder-tampão do Latossolo Bruno, cuja textura é muito argilosa e possui elevados teores de matéria orgânica.

Contrariando os resultados obtidos neste experimento, King et al. (1974) verificaram que os

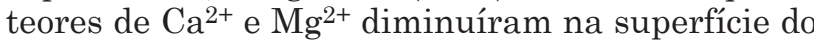
solo após a adição de esterco de aves, sendo justificado pelo incremento dos teores de $\mathrm{K}$, o qual compete com $\mathrm{Ca}^{2+} \mathrm{e} \mathrm{Mg}^{2+}$ nas superfícies sortivas do solo.

A mobilidade do $\mathrm{Ca}^{2+}$ e do $\mathrm{Mg}^{2+}$, em profundidade, favorece o desenvolvimento radicular das plantas (Stone \& Silveira, 2001), permitindo maior capacidade de absorção de água e nutrientes do solo (Pavan, 1999), tendo como conseqüência maior resistência a condições climáticas adversas e melhor aproveitamento dos nutrientes.
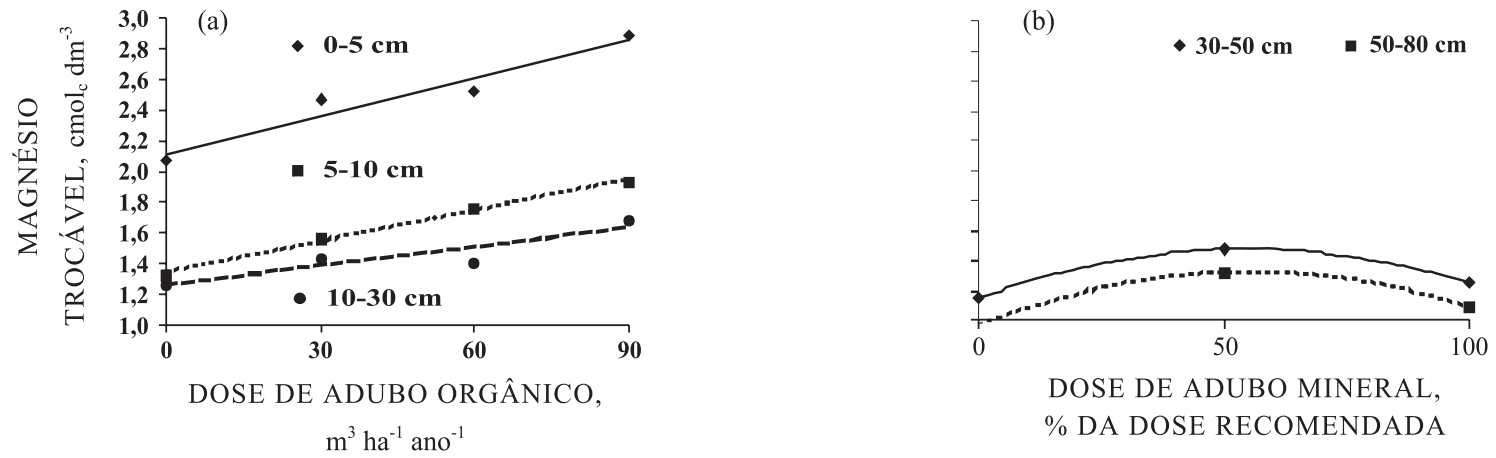

Figura 4. Teor de magnésio trocável em Latossolo Bruno sob plantio direto submetido a diferentes doses de esterco líquido de gado de leite e adubação mineral, por um período de seis anos, com remoção total da planta: (a) adubação orgânica; (b) adubação mineral. 


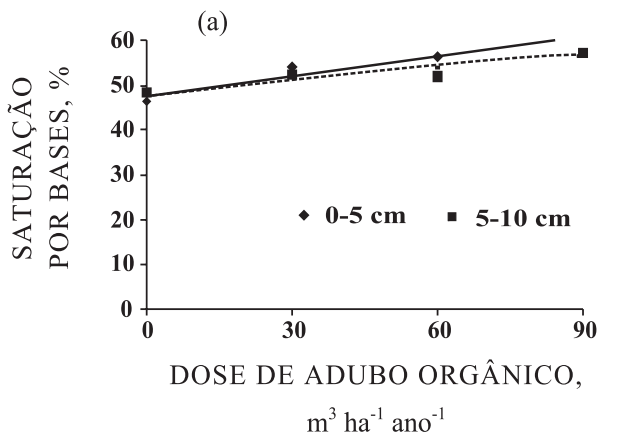

(b)

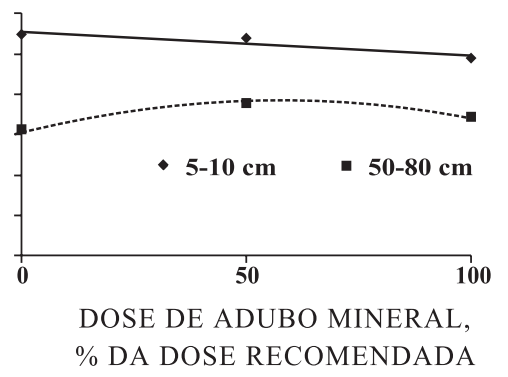

Figura 5. Saturação por bases (V) em Latossolo Bruno sob plantio direto submetido a diferentes doses de esterco líquido de gado de leite e adubação mineral, por um período de seis anos, com remoção total da planta: (a) adubação orgânica; (b) adubação mineral.

A saturação por bases foi afetada apenas pelo efeito simples do esterco líquido de gado leiteiro nas profundidades de $0-5$ e $5-10 \mathrm{~cm}$, sendo coerente, portanto, com o aumento do $\mathrm{pH}$ e dos teores de Ca e Mg e com a redução da acidez potencial verificados nessas camadas. Contrariamente ao observado, Schjonning et al. (1994) constataram diminuição da saturação de bases na camada de 0-20 cm pelo uso de esterco, em razão do acréscimo na acidez potencial. Contudo, a camada inferior não foi afetada pelo uso de esterco.

\section{CONCLUSÕES}

1. O efeito da adubação do solo com esterco líquido de gado de leite combinado com adubação mineral ocorreu de maneira isolada, ou seja, não há interação entre eles.

2. A adubação com esterco favoreceu o aumento do $\mathrm{pH}$ na camada superficial do solo de $0-5 \mathrm{~cm}$, enquanto a adubação mineral promoveu acidificação do solo, até a profundidade de $10 \mathrm{~cm}$.

3. O esterco líquido de gado de leite foi eficiente em elevar o teor de $\mathrm{Ca}^{2+}$ na superfície do solo $(0-5 \mathrm{~cm})$, enquanto a adubação mineral não influenciou os teores de $\mathrm{Ca}^{2+}$ no solo.

4. A adubação com esterco foi eficiente em aumentar os teores de $\mathrm{Mg}^{2+}$ até a profundidade de $30 \mathrm{~cm}$. A adubação mineral incrementou os teores de $\mathrm{Mg}^{2+}$ apenas em profundidade superior a $30 \mathrm{~cm}$.

\section{LITERATURA CITADA}

ABREU JUNIOR, C.H.; MURAOKA, T.; LAVORANTE, A.F. \& ALVAREZ V., F.C. Condutividade elétrica, reação do solo e acidez potencial em solos adubados com composto de lixo. R. Bras. Ci. Solo, 24:635-647, 2000.

ANJOS, A.R.M. \& MATTIAZZO, M.E. Lixiviação de íons inorgânicos em solos repetidamente tratados com biossólido. R. Bras. Ci. Solo, 24:927-938, 2000.
CHANG, C.; SOMMERFELDT, T.G. \& ENTZ, T. Rates of soil chemical changes with eleven annual applications of cattle feedlot manure. Can. J. Soil Sci.,70:673-681, 1990.

CHANG, C.; SOMMERFELDT, T.G. \& ENTZ, T. Soil chemistry after eleven annual applications of cattle feedllot manure. J. Environ. Qual., 20:475-480, 1991.

EMPRESA BRASILEIRA DE PESQUISA AGROPECUÁRIA EMBRAPA. Centro Nacional de Pesquisa de Solos. Sistema brasileiro de classificação de solos. Brasília, Produção de Informação, 1999. 412p.

ERNANI, P.R. \& GIANELLO, C. Diminuição do alumínio trocável do solo pela incorporação de esterco de bovinos e camas de aviário. R. Bras. Ci. Solo, 7:161-165, 1983.

FOLLETT, R.F. \& PETERSON, G.A. Surface soil nutrient distribution as affected by wheat-fallow tillage systems. Soil Sci. Soc. Am. J., 52:141-147, 1988.

FOX, R.H. \& HOFFMAN, L.D. The effect of N fertilizer source on grain yield, $\mathrm{N}$ uptake, soil $\mathrm{pH}$, and lime requirement in no-till corn. Agron. J., 73:891-895, 1981.

FRANCHINI, J.C.; MALAVOLTA, E.; MIYAZAWA, M. \& PAVAN, M.A. Alterações químicas em solos ácidos após a aplicação de resíduos vegetais. R. Bras. Ci. Solo, 23:533542,1999 .

GROVE, J.H. The development and control of surface soil acidity under conservation tillage. J. Fert., 3:52-61, 1986.

HAMMEL, J.E. Long-Term tillage and crop rotation effects on bulk density and soil impedance in Northern Idaho. Soil Sci. Soc. Am. J., 53:1515-1519,1989.

HOLANDA, J.S.; MIELNICZUK, J. \& STAMMEL, J.G. Utilização de esterco e adubo mineral em quatro seqüências de culturas em solo de encosta basáltica do Rio Grande do Sul. R. Bras. Ci. Solo, 6:47-51, 1982.

HOYT, P.B. \& TURNER, R.C. Effects of organic materials added to very acid soils, on $\mathrm{pH}$, aluminum, exchangeable $\mathrm{NH}_{4}$, and crop yield. Soil Sci., 119:227-237, 1975.

HUE, N.V. \& AMIEN, I. Aluminum detoxification with green manures. Comm. Soil Sci. Plant Anal., 20:1499-1511, 1989. 
HUE, N.V. Correcting soil acidity of highly weathered ultisol with chicken manure and sewage sludge. Comm. Soil Sci. Plant Anal., 23:241-264, 1992.

INSTITUTO AGRONÔMICO DO PARANÁ - IAPAR. Cartas climáticas do Estado do Paraná. Londrina, 2000. CD-ROM

ISMAIL, I.; BLEVINS, R.L. \& FRYE, W.W. Long-term no tillage effects on soil properties and continuous corn yields. Soil Sci. Soc. Am. J., 58:193-198, 1994.

IYAMUREMYE, F.; DICK, R.P. \& BAHAM, J. Organic amendments and phosphorus dynamics: I. Phosphorus chemistry and sorption. Soil Sci., 161:426-435, 1996.

JOSAN, M.S.; NAIR, V.D.; HARRIS, W.G. \& HERRERA, D. Associated release of magnesium and phosphorus from active and abandoned dairy soils. J. Environ. Qual., 34:184$191,2005$.

JUO, A.S.R.; DABIRI, A. \& FRANZLUEBBERS, K. Acidification of a kaolinitic Alfisol under continuous cropping with nitrogen fertilization in West Africa. Plant Soil, 171:245-253, 1995

KINGERY, W.L.; WOOD, C.W.; DELANEY, D.P.; WILLIAMS, J.C. \& MULLINS, G.L. Impact of long-term land application of broiler litter on environmentally related soil properties. J. Environ. Qual., 23:139-147, 1994.

KING, L.D.; RUDGERS, L.A. \& WEBBER, L.R. Application of municipal refuse and liquid sewage sludge to agricultural land: I field study. J. Environ. Qual., 3:361-366,1974.

LOYOLA, E. \& PAVAN, M.A. Seletividade de troca de cátions em solos ácidos. R. Bras. Ci. Solo, 13:131-138, 1989.

MARQUES, R. \& MOTTA, A.C.V. Análise química do solo para fins de fertilidade. In: LIMA, M.R.; SIRTOLI, A.E.; SERRAT, B.M.; WISNIEWSKI, C.; ALMEIDA, L.; MACHADO, M.A.M.; MARQUES, R.; MOTTA, A.C.V.; KRIEGER, K.I.; OLIVEIRA, A.C. \& FERREIRA, F.V., eds. Manual de diagnóstico da fertilidade e manejo dos solos agrícolas. 2.ed. Curitiba, Universidade Federal do Paraná, 2003. p.81-102.

McVAY, K.A.; RADCLIFFE, D.E. \& HARGROVE, W.L. Winter legume effects on soil properties and nitrogen fertilizer requirements. Soil Sci. Soc. Am. J., 53:1856-1862, 1989.
MOTTA, A.C.V. Soil management impact soil quality in the Tennessee Valley of Northern Alabama. Auburn, Auburn University, 2002. 153p.

OLSEN, R.J.; HENSLER, R.F. \& ATTAO, O.J. Effect of manure application, aerations, soil $\mathrm{pH}$ on soil nitrogen transformations and on certain soil test values. Soil Sci. Soc. Am. Proc., 34:222-225, 1970.

PAIVA, P.J.R.; VALE, F.R.; FURTINI NETO, A.E. \& FAQUIN, V. Acidificação de um Latossolo roxo do estado do Paraná sob diferentes sistemas de manejo. R. Bras. Ci. Solo, 24:7175, 1996.

PAVAN, M.A. Mobilização orgânica do calcário no solo através de adubo verde. In: PAULETTI, V. \& SEGANFREDO, R. Plantio direto: Atualizações tecnológicas. Castro, Fundação Cargill, 1999. p.45-52.

RAIJ, B.van. Fertilidade do solo e adubação. Piracicaba, Ceres/ Potafos, 1991. 343p.

STATISTICAL ANALYSIS SYSTEM - SAS System for linear models. Cary: SAS Institute, 6.ed. 1996. 956p.

SCHJONNING, P.; CHRISTENSEN, B.T. \& CARSTENSEN, B. Physical and chemical properties of a sandy loam receiving animal manure, mineral fertilizer or no fertilizer for 90 years. Eur. J. Soil Sci., 45:257-268, 1994.

STONE, L.F. \& SILVEIRA, P.M. Efeitos do sistema de preparo e da rotação de culturas na porosidade e densidade do solo. R. Bras. Ci. Solo, 25:395-401, 2001.

WARMAN, P.R. The effects of pruning, fertilizers, and organic amendments on lowbush blueberry production. Plant Soil, 101:67-72, 1987.

WHALEN, J.K.; CHANG, C.; CLAYTON, G.W. \& CAREFOOT, J.P. Cattle manure amendments can increase the $\mathrm{pH}$ of acid soils. Soil Sci. Soc. Am. J., 64:962-966, 2000.

VITOSH, M.L.; DAVIS, J.F. \& KNEZEK, B.D. Long-term effects of manure, fertilizer, and plow depth on chemical properties of soils and nutrient movement in a monoculture corn system. J. Environ. Qual., 2:296-299, 1973. 